\title{
Correlation between Saliva and Plasma Levels of Endothelin Isoforms ET-1, ET-2, and ET-3
}

\author{
Roma Gurusankar, ${ }^{1}$ Prem Kumarathasan, ${ }^{2}$ Anusha Saravanamuthu, ${ }^{2}$ \\ Errol M. Thomson, ${ }^{1}$ and Renaud Vincent ${ }^{1}$ \\ ${ }^{1}$ Inhalation Toxicology Laboratory, Environmental Health Science and Research Bureau, Health Canada, \\ Ottawa, ON, Canada K1A 0K9 \\ ${ }^{2}$ Analytical Biochemistry and Proteomics Laboratory, Environmental Health Science and Research Bureau, Health Canada, \\ Ottawa, ON, Canada K1A OK9 \\ Correspondence should be addressed to Renaud Vincent; renaud.vincent@hc-sc.gc.ca
}

Received 17 January 2015; Revised 17 March 2015; Accepted 18 March 2015

Academic Editor: Kazuhiro Takahashi

Copyright (C) 2015 Roma Gurusankar et al. This is an open access article distributed under the Creative Commons Attribution License, which permits unrestricted use, distribution, and reproduction in any medium, provided the original work is properly cited.

\begin{abstract}
Although saliva endothelins are emerging as valuable noninvasive cardiovascular biomarkers, reports on the relationship between isoforms in saliva and plasma remain scarce. We measured endothelins in concurrent saliva and plasma samples $(n=30$ males; age 18-63) by HPLC-fluorescence. Results revealed statistically significant positive correlations among all isoforms between saliva and plasma: big endothelin-1 (BET-1, $0.55 \pm 0.27$ versus $3.35 \pm 1.28 \mathrm{pmol} / \mathrm{mL} ; r=0.38, p=0.041$ ), endothelin-1 (ET-1, $0.52 \pm 0.21$ versus $3.45 \pm 1.28 \mathrm{pmol} / \mathrm{mL} ; r=0.53, p=0.003)$, endothelin-2 (ET-2, $0.21 \pm 0.07$ versus $1.63 \pm 0.66 \mathrm{pmol} / \mathrm{mL} ; r=0.51, p=0.004)$, and endothelin-3 (ET-3, $0.39 \pm 0.19$ versus $2.32 \pm 1.44 \mathrm{pmol} / \mathrm{mL} ; r=0.75, p<0.001$ ). Correlations of BET-1, ET-1, and ET-3 within each compartment were positive in both plasma $(p<0.05)$ and saliva $(p \leq 0.1)$, whereas ET-2 was not significantly correlated with other isoforms in either plasma or saliva. For all isoforms, concentrations varied on average fivefold between individuals (90th/10th percentiles); individuals with high plasma endothelin levels generally had high saliva endothelin levels. Our results reveal that salivary ET isoform profiles portray the plasmatic profiles and support the view of coordinated regulation of ET-1 and ET-3, but distinct regulatory pathways for ET-2.
\end{abstract}

\section{Introduction}

As a diagnostic fluid, saliva has several advantages over blood $[1,2]$. Saliva is inexpensive and easier to collect, and sufficient volume can be obtained to allow performance of a variety of analyses. For patients, particularly children, the noninvasive sample collection reduces anxiety and discomfort and simplifies procurement of repeated samples for time-series analyses. Saliva contains a wide array of proteins and peptides that are responsive to pathological conditions [3]. Advanced instrumentation and refined analytical techniques have been successfully applied for discovering oncological [4], hormonal [5], immunological [6], and cardiovascular [7, 8] biomarkers that can be informative for early detection and assessment of progression of oral and systemic diseases.

Of particular interest, saliva is known to contain detectable levels of endothelins, an important risk marker for cardiovascular disease [9]. Endothelins are a family of potent vasoconstrictor peptides consisting of three distinct isoforms, endothelin-1 (ET-1), endothelin-2 (ET-2), and endothelin-3 (ET-3) coded by distinct genes [10]. The mature endothelins are produced through cleavage of the big endothelin (BET) precursors by endothelin-converting enzymes [11, 12]. Endothelin-1, the most studied isoform, has been implicated in several diseases, particularly in the progression of cardiovascular diseases $[13,14]$. It has been known for two decades that ET-1, ET-2, and ET-3 are present in saliva $[15,16]$. However, only recently have levels of saliva ET-1 been related to conditions such as chronic heart failure [17], upper gastrointestinal diseases [18], vibration-induced white finger [19], and oral cancer [20,21]. The relationship between saliva and plasma ET-2 and ET-3 isoforms is comparatively less well understood. Because of the emerging significance of all three isoforms in health and disease, notably the role of ET-2 in 
the cardiovascular system, in ovulation, immunology, and cancer [22], we sought to extend the data on the relationships between the three endothelin isoforms in concurrent saliva and plasma samples.

\section{Materials and Methods}

2.1. Reagents. Ethylenediaminetetraacetic acid (EDTA), trifluoroacetic acid (TFA), phenylmethyl sulfonyl fluoride (PMSF), 3,4-dichloroisocoumarin, molecular weight cut-off filters $(30 \mathrm{kDa})$, endothelin-1 (ET-1, human), endothelin2 (ET-2, human), and endothelin-3 (ET-3, human) were obtained from Sigma Aldrich (Oakville, Ontario). Big endothelin-1 (BET-1, human) was obtained from Bachem Bioscience (American Inc., CA, USA). Acetonitrile, acetone, methanol, and hydrochloric acid were purchased from Sigma Aldrich (Oakville, Ontario). Amber glass vials and screwcaps with septa were purchased from Chromatographic Specialities (Brockville, Ontario). Deionized water was obtained from a Super-Q Plus high purity water system (Millipore Corporation, Bedford, MA). Compressed gaseous nitrogen was of UHP grade quality and was supplied by Matheson Gas Products (Whitby, Ontario).

2.2. Biological Samples. Anonymous, paired human plasma and saliva samples (from males) certified free of HIV, HEPA, and HEP-B were purchased commercially (Innovative Research Inc., MI). Saliva samples were collected by spitting in a sterile cup, without stimulation. Both plasma and saliva samples were treated on site with PMSF (final, $1.7 \mathrm{mg} / \mathrm{mL}$ ) and EDTA (final, $10 \mathrm{mg} / \mathrm{mL}$ ) to stabilize endothelins [23], shipped to our laboratory in dry ice, and stored at $-80^{\circ} \mathrm{C}$ until further use. Saliva samples containing phlegm or low volume of fluid were discarded. Thirty (30) sample pairs of good quality and in sufficient amounts for analysis were retained for this study.

\subsection{Extraction of Endothelins from Plasma and Saliva.} Plasma and saliva endothelins were extracted following Kumarathasan et al. [23]. Briefly, plasma $(250 \mu \mathrm{L})$ and saliva $(1 \mathrm{~mL})$ samples were treated with ice-cold 3,4-dichloroisocumarin solution in isopropanol to prevent conversion of BET-1 to ET-1 during the sample processing. The samples were deproteinized with ice-cold acid-acetone mix (acetone: $1 \mathrm{~N}$ $\mathrm{HCl}$ : water, $40: 1: 5)$ and centrifuged at $9000 \times \mathrm{g}$ for $10 \mathrm{~min}$, and the supernatants obtained were concentrated by evaporation under nitrogen flow. Deproteinization and concentration stages were repeated once more to ensure the removal of abundant proteins. Samples were then loaded onto $30 \mathrm{kDa}$ molecular weight cut-off filters (prewashed with deionised water) and centrifuged at $5000 \times \mathrm{g}$ for $30 \mathrm{~min}$. These filters were then washed with $50 \%$ methanol and centrifuged at $5000 \times \mathrm{g}$ for $30 \mathrm{~min}$. Filtrates were dried under nitrogen and reconstituted in $75 \mu \mathrm{L}$ of $30 \%$ acetonitrile in $0.2 \%$ TFA/ $\mathrm{H}_{2} \mathrm{O}$ for HPLC-fluorescence analysis.

2.4. HPLC-Fluorescence Analysis of Endothelins. The HPLC unit consisted of a Gilson solvent delivery system (Mandel
Scientific, Guelph, ON), a Gilson autosampler (model $231 \mathrm{XL}$; Middleton, WI), a Supelcosil LC-318 reverse-phase column (25 cm length, $4.6 \mathrm{~mm}$ id, $5 \mu \mathrm{m}$ particle size, and $300 \AA$ pore dimension; Supelco, Oakville, ON), and a RF 551 model fluorescence detector (Shimadzu, Japan). Endothelins ( $20 \mu \mathrm{L}$ injection volume) were separated using a gradient elution with acetonitrile/water mobile phase at a flow rate of $1 \mathrm{~mL} / \mathrm{min}$ and detected at $\boldsymbol{\lambda}_{\mathrm{EX}} 280 \mathrm{~nm}$ and $\boldsymbol{\lambda}_{\mathrm{EM}} 340 \mathrm{~nm}$ [23]. Blanks were analyzed after each set of four samples in order to assess the extent of analyte carryover.

2.5. Statistical Analyses. Student's t-test or Mann-Whitney Rank Sum Test was carried out as appropriate using SigmaStat v 11.0 (SPSS Inc., Chicago, IL). Results are presented as mean \pm standard deviation. Correlation between different endothelin isoforms in plasma and saliva was tested using Pearson's Product Moment correlation revealing $p$ and $r$ values. Statistical significance was accepted for $\alpha=0.05$.

\section{Results and Discussion}

We used HPLC-fluorescence to measure simultaneously the isoforms BET-1, ET-1, ET-2, and ET-3 (Figures 1(a)-1(b)) in time-matched plasma and saliva sample pairs $(N=30)$ obtained from anonymous individuals (Table 1). Our results confirm and extend previous reports of the presence of endothelins in saliva $[15,16]$ and of a relationship between saliva and circulating endothelins [17-19], and the correlated measurements provide additional insight into the relationship of ET-2 to the other two isoforms [22]. The recoveries, analytical precision, and accuracy of the HPLC-fluorescence procedure [23] are comparable to values reported by Walczak et al. for HPLC with electrospray tandem mass spectrometry detection [24]: recoveries of endothelins from spiked plasma are between $60 \%$ (ET-2) and $97 \%$ (ET-1), depending on the endothelin isoforms; analytical precision is on the order of $\pm 4 \%$ for replicate peptide standards; analytical accuracy is $\pm 20 \%$ for replicate measurements of plasma samples; limit of detection is $0.2-0.5 \mathrm{pmol}$; and linearity is $1-100 \mathrm{pmol}$ on the column $(20 \mu \mathrm{L}$ injection volume). Both methods detect the separated peptides directly (i.e., on the basis of autofluorescence of aromatic amino acids by HPLC [23, 25] or from mass ion fingerprints in MS/MS [24]), which is different from ELISA detection of immunoreactive endothelin in total plasma [26, 27]. For this reason, we have verified identities of analytes by pulling down of ET-1 and ET-3 with monoclonal antibodies during sample processing, confirming the correspondence between immunoreactive endothelins in plasma and the peptides measured by direct autofluorescence detection after separation on column [23].

It should be noted that the aim of our study was not to explore the physiological significance of variations of saliva and plasma endothelin levels, within and between individuals, and for this reason we have not requested any information on the health status, cardiovascular or buccal, of the donors. Salivary secretions and saliva volume will be affected by water and food uptake and by medication. These factors, together with the health status of subjects and sample quality, can 
TABLE 1: Plasma and saliva endothelin levels (mean \pm SD) in male subjects.

\begin{tabular}{|c|c|c|c|c|c|c|}
\hline & BET-1 & ET-1 & ET-2 & ET-3 & Total & BET-1/ET-3 \\
\hline \multicolumn{7}{|l|}{ Plasma $(\mathrm{pmol} / \mathrm{mL})$} \\
\hline All (30) & $3.35 \pm 1.28$ & $3.45 \pm 1.28$ & $1.63 \pm 0.66$ & $2.32 \pm 1.44$ & $10.8 \pm 3.46$ & $1.84 \pm 1.00$ \\
\hline $18-40$ years (19) & $3.39 \pm 1.38$ & $3.22 \pm 1.43$ & $1.56 \pm 0.61$ & $1.97 \pm 1.21$ & $10.1 \pm 3.7$ & $2.10 \pm 1.07$ \\
\hline \multirow[t]{2}{*}{ 41-63 years (11) } & $3.29 \pm 1.15$ & $3.87 \pm 0.89$ & $1.77 \pm 0.73$ & $2.91 \pm 1.67$ & $11.8 \pm 2.9$ & $1.38 \pm 0.70$ \\
\hline & & & & $P=0.039$ & & $P=0.043$ \\
\hline \multicolumn{7}{|l|}{ Saliva $(\mathrm{pmol} / \mathrm{mL})$} \\
\hline All (30) & $0.55 \pm 0.27$ & $0.52 \pm 0.21$ & $0.21 \pm 0.07$ & $0.39 \pm 0.19$ & $1.68 \pm 0.53$ & $1.61 \pm 0.75$ \\
\hline $18-40$ years (19) & $0.59 \pm 0.32$ & $0.56 \pm 0.25$ & $0.20 \pm 0.07$ & $0.37 \pm 0.16$ & $1.71 \pm 0.64$ & $1.68 \pm 0.66$ \\
\hline 41-63 years (11) & $0.49 \pm 0.12$ & $0.47 \pm 0.13$ & $0.23 \pm 0.09$ & $0.43 \pm 0.23$ & $1.62 \pm 0.27$ & $1.48 \pm 0.91$ \\
\hline \multicolumn{7}{|l|}{ Plasma/saliva } \\
\hline All (30) & $6.94 \pm 3.30$ & $7.05 \pm 2.58$ & $8.18 \pm 3.16$ & $6.15 \pm 2.34$ & $6.67 \pm 1.79$ & \\
\hline $18-40(19)$ & $6.86 \pm 3.50$ & $6.11 \pm 2.16$ & $8.16 \pm 3.18$ & $5.71 \pm 2.73$ & $6.30 \pm 1.93$ & \\
\hline \multirow[t]{2}{*}{$41-63(11)$} & $7.07 \pm 3.10$ & $8.67 \pm 2.51$ & $8.22 \pm 3.28$ & $6.89 \pm 1.25$ & $7.31 \pm 1.36$ & \\
\hline & & $P=0.006$ & & & & \\
\hline
\end{tabular}

Note: $P$ value for comparison between the two age groups ( $t$-test or Mann-Whitney Rank Sum Test). The number of subjects is shown in parentheses.

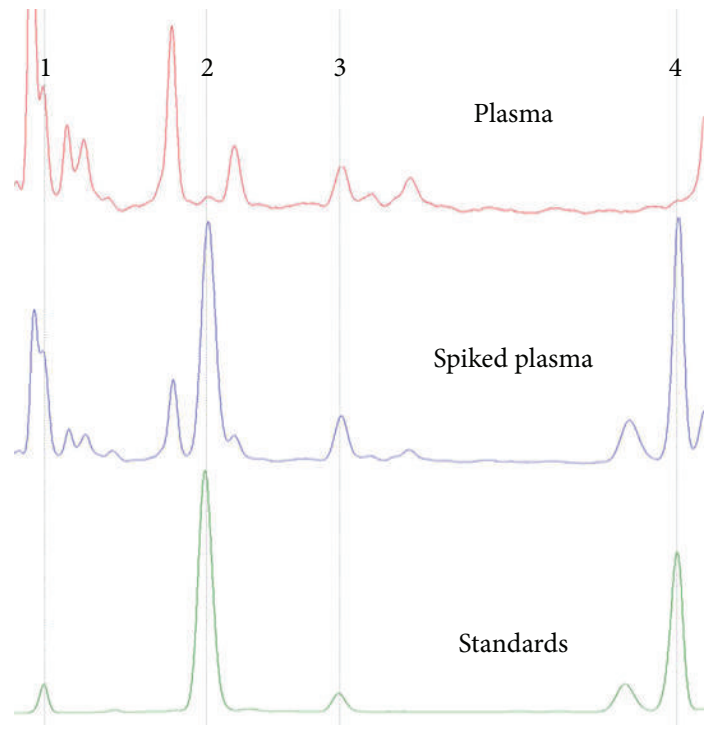

(a)

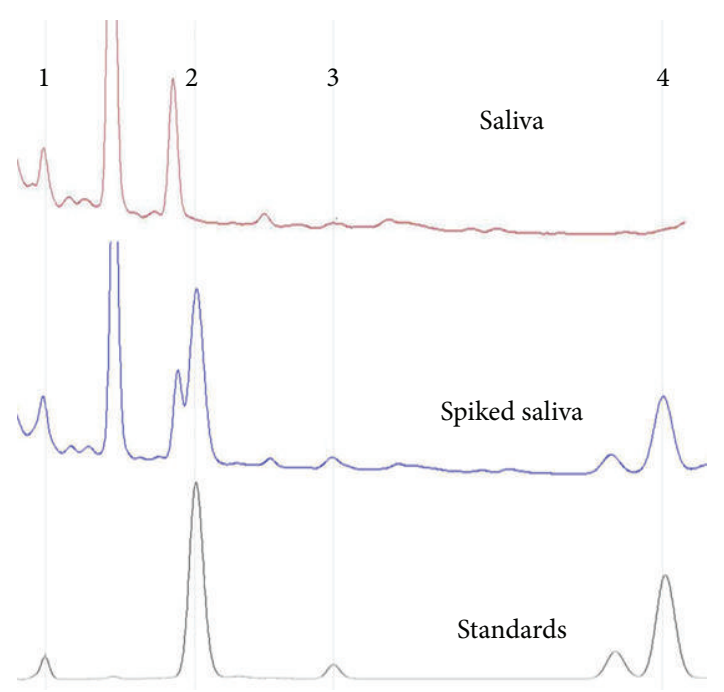

(b)

Figure 1: HPLC profiles of endothelin isoforms ET-3 (1), BET-1 (2), ET-1 (3), and ET-2 (4) in human (a) plasma and (b) saliva samples (including unspiked and spiked biological matrices along with endothelin standards).

contribute to the variance in observed saliva endothelin concentrations and relationship to plasma levels. Furthermore, sample collection procedures, sample preparation methods, matrix effects, and the analytical approach used are likely to impact the absolute values of estimates. Finally, because all samples analyzed for endothelin content in our small study were from male donors, our data do not address potential gender differences.

Notwithstanding those limitations, our observations reveal that levels of all endothelin isoforms were significantly correlated between the saliva and plasma matrices in the subjects studied: BET-1 $(r=0.38, p=0.041)$, ET-1 $(r=0.53$, $p=0.003)$, ET-2 $(r=0.51, p=0.004)$, and ET-3 $(r=0.75$, $p<0.001$ ) (Table 1, Figure 2). Our results indicate a slight increase in the ratios of endothelin levels in plasma versus saliva with age of the subjects (ET-1, plasma/saliva ratio in 1840 years versus $41-63$ years, $6.11 \pm 2.16$ versus $8.67 \pm 2.51, p=$ 0.006 ), which is potentially attributable to saliva osmolality changes with age $[28,29]$. Interestingly, the relationship between osmolality changes and endothelin system has been previously reported [30]. Endothelin levels varied on average by fivefold between individuals, and this applied to all four isoforms measured, in plasma as well as saliva (90th/10th percentiles). In general, high BET-1 and ET-1 levels were predictive of high ET-3 levels within an individual (Table 2). Within plasma, a significant positive correlation was seen for BET-1 versus ET-1 ( $r=0.39, p=0.033)$, BET-1 versus ET-3 $(r=0.46, p=0.011)$, and ET-1 versus ET-3 $(r=0.57, p=$ $0.001)$. Within saliva, a significant positive correlation was seen for BET-1 versus ET-1 $(r=0.75, p<0.001)$. Correlations 
TABLE 2: Pearson product moment correlation ( $r$-value) for endothelin isoforms in plasma (PL) and saliva (SL) of male subjects $(n=30)$.

\begin{tabular}{lccccccc}
\hline & ET-1 PL & ET-2 PL & ET-3 PL & BET-1 SL & ET-1 SL & ET-2 SL & ET-3 SL \\
\hline BET-1 PL & $0.39(0.033)$ & $0.27(0.157)$ & $0.46(0.011)$ & $0.38(0.041)$ & $0.30(0.110)$ & $-0.11(0.571)$ & $0.41(0.024)$ \\
ET-1 PL & & $0.25(0.183)$ & $0.57(0.001)$ & $0.31(0.093)$ & $0.53(0.003)$ & $-0.22(0.251)$ & $0.46(0.011)$ \\
ET-2 PL & & & $0.13(0.511)$ & $0.01(0.974)$ & $0.15(0.434)$ & $0.51(0.004)$ & $0.16(0.406)$ \\
ET-3 PL & & & & $0.17(0.383)$ & $0.16(0.409)$ & $-0.29(0.121)$ & $0.75(<0.001)$ \\
BET-1 SL & & & & & $0.75(<0.001)$ & $-0.12(0.534)$ & $0.31(0.091)$ \\
ET-1 SL & & & & & & $-0.13(0.491)$ & $0.27(0.144)$ \\
ET-2 SL & & & & & & $-0.167(0.378)$ \\
\hline
\end{tabular}

Note: $P$ values are given in parentheses.

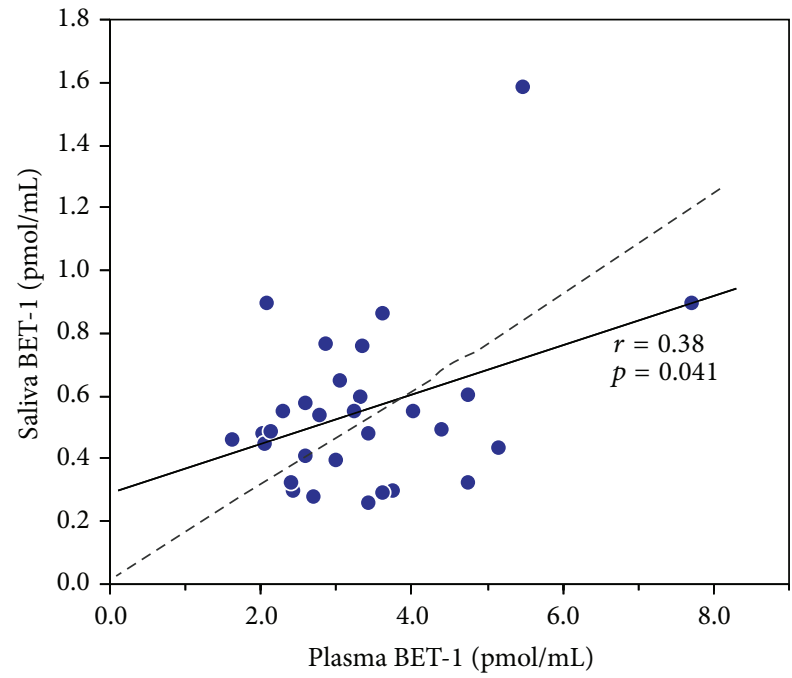

(a)

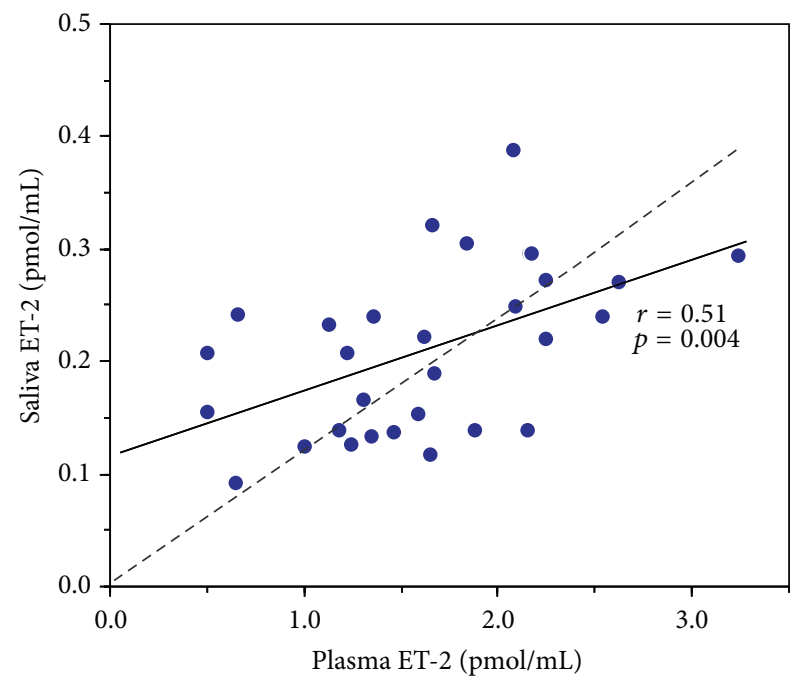

(c)

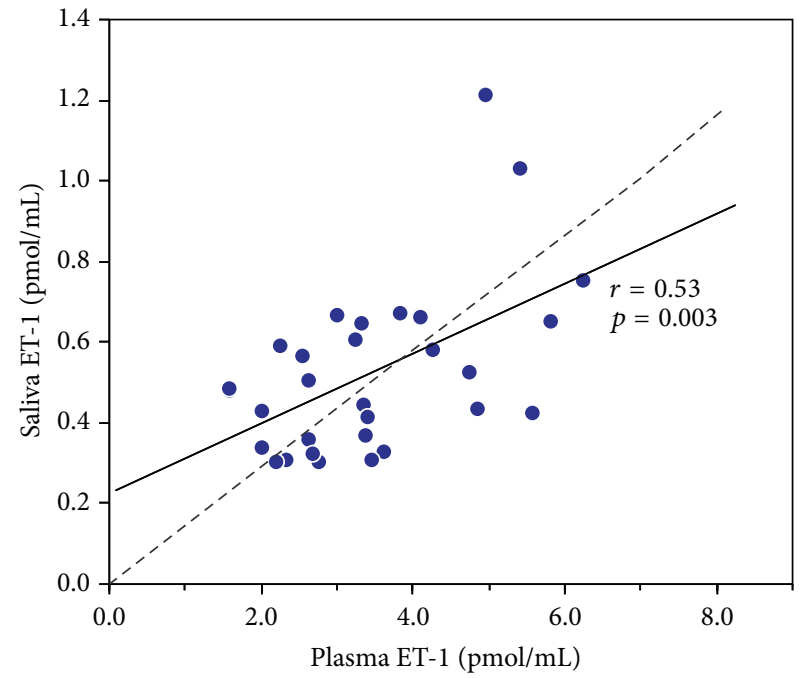

(b)

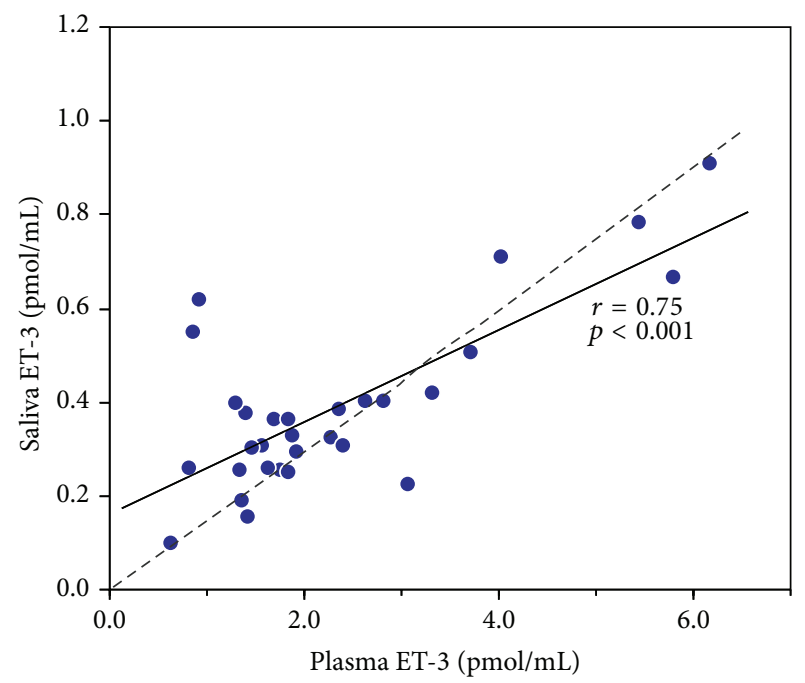

(d)

FIGURE 2: Correlation between endothelin isoforms BET-1 (a), ET-1 (b), ET-2 (c), and ET-3 (d) in plasma and saliva of male subjects $(n=$ 30) measured by HPLC-fluorescence. Assuming simple linearity, the linear regression (solid line) intercept on saliva axis is an estimate of salivary gland endothelin production ( $r$ and $p$ values indicated). The linear regression forced through zero (dashed line) assumes diffusion of endothelins entirely from plasma. 


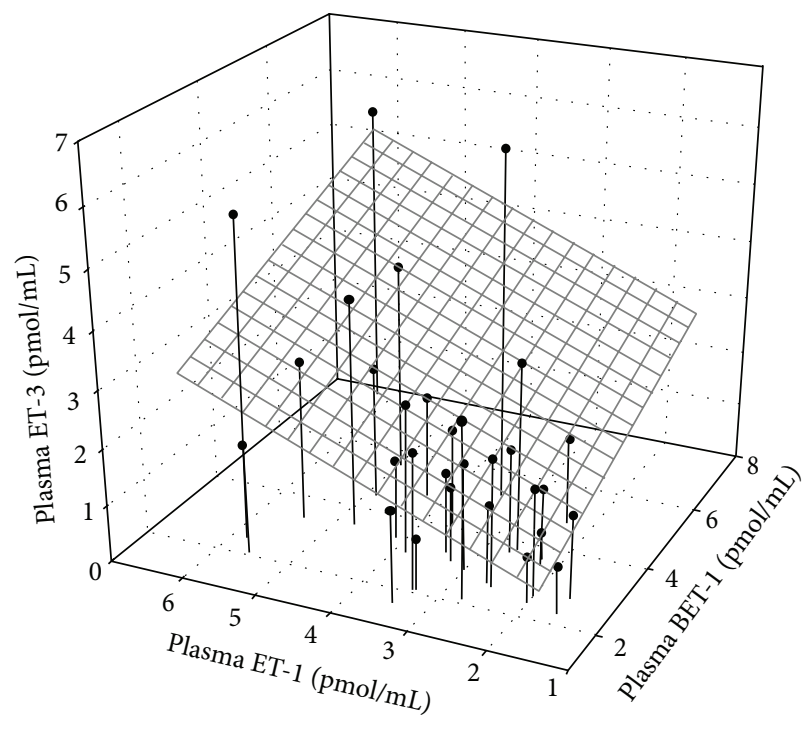

(a)

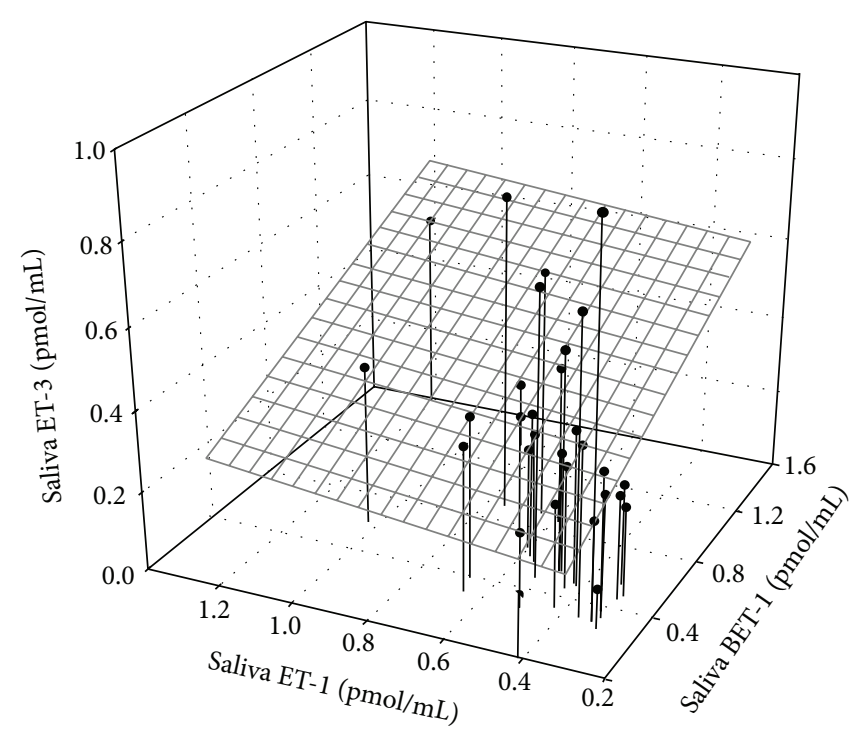

(b)

FIGURE 3: Correlation between BET-1, ET-1, and ET-3 isoforms in plasma (a) and saliva (b) of male subjects.

between BET-1 versus ET-3 $(r=0.31, p=0.091)$ and ET-1 versus ET-3 $(r=0.27, p=0.144)$ in saliva were not significant. There were no significant correlations between ET-2 and other isoforms in either plasma or saliva.

The origin of saliva endothelins is not well established. Whole saliva contains secretions from the major parotid, submandibular and sublingual glands, the palate, buccal and labial mucosa, and so on [31]. Expression of preproET-1 and preproET-3 as well as the $\mathrm{ET}_{\mathrm{A}}$ and $\mathrm{ET}_{\mathrm{B}}$ receptors has been detected by RT-PCR analyses of submandibular glands of rats [32]. Endothelin-1 has also been detected in striated duct cells of human salivary glands by immunohistochemical analysis [33]. Therefore, it is plausible that endothelins are secretory products from salivary glands. However, serum molecules that are not part of the normal salivary secretory constituents, such as proteins, drugs, and hormones, can also reach saliva by passive diffusion [1, 2, 34-36]. We have measured six- to eightfold higher concentrations of endothelins in plasma by comparison to saliva, and hence the concentration gradient may result in diffusion of the peptides from the capillaries of the mucosa into the salivary fluid. If the intercept of the linear regressions of saliva versus plasma endothelin concentrations is taken as an estimate of the contribution by salivary glands, then at least half (BET-1, ET-1, and ET-2) to two-thirds (ET3 ) of the salivary endothelins may originate from plasma (Figure 2).

Correlation among the different endothelin isoforms within individuals and the large variance of endothelin levels between individuals may be due to a number of factors, including common regulatory mechanisms, genetic polymorphisms, and physiological status. Correlation between BET-1 and ET-1 should be expected because of the direct precursor-product relationship [37]. Furthermore, endothelin converting enzyme-1, which cleaves BET-1 to ET-1, shares some regulatory elements with the preproET-1 gene, such that when preproET-1 is transcriptionally activated, ECE-1 tends to be activated as well [38]. In healthy individuals, ET-1 plays an important role in the modulation of vasomotor tone, in conjunction with nitric oxide, but also in regulating cellular proliferation and differentiation in tissues during growth, development, and repair $[39,40]$.

There is good evidence for coordinated regulation of ET1 and ET-3. In individuals with high basal ET-1 production, activation of preproET-3 expression through a feedback control mechanism may compensate for the pressor effects of the high circulating levels of ET-1. Endothelin-3 stimulates nitric oxide synthase expression and NO production through binding to the $\mathrm{ET}_{\mathrm{B}}$ receptor [41], and increase of ET-1 with a decrease of ET-3, due to endothelial dysfunction, has been reported in patients with pulmonary arterial hypertension of various etiologies $[42,43]$. It is also possible that high or low transcriptional activity of both preproET-1 and preproET-3 genes within an individual is determined by genetic polymorphism or epigenetic conditioning of transacting elements with common cis-acting regulatory sequences between the two genes, but this remains to be investigated. In our analyses, the strongest associations were seen between saliva ET-3 and plasma ET-3 $(r=0.75, p<0.001)$ and between saliva BET-1 and saliva ET-1 $(r=0.75, p<0.001)$. An overall relationship between ET- 3 and BET-1 and its mature product ET- 1 was observed in plasma and saliva but was stronger in plasma (Figure 3). The similar ratio of BET-1 to ET-1 in plasma (3.35 versus $3.45 \mathrm{pmol} / \mathrm{mL}$ ) and saliva ( 0.55 versus $0.52 \mathrm{pmol} / \mathrm{mL}$ ) suggests a relative stability of the peptides during sampling and sample processing. However, although saliva ET-2 correlated with plasma ET-2 $(r=0.51, p=0.004)$, the poor correlation between ET-2 and the other endothelin isoforms, within plasma (positive, $p>0.05$ ) and within saliva (negative, $p>0.05$ ), is in line with the concept of ET-2 regulatory pathways distinct from those of ET-1 and ET-3 [22]. 
In conclusion, our data confirm an overall positive correlation between plasmatic and salivary BET-1, ET-1, ET-2, and ET-3 levels and between the BET-1, ET-1, and ET-3 within each of the two compartments. The isoform ET-2 correlates poorly with ET-1 and ET-3, within saliva and within plasma. Salivary ET isoform profiles portray the plasmatic profiles and support the view of coordinated regulation of ET-1 and ET-3, but distinct regulatory pathways for ET-2.

\section{Abbreviations}

ET: Endothelin

ECE: Endothelin-converting enzyme

EDTA: Ethylenediaminetetraacetic acid

HEP-A: Hepatitis A

HEP-B: Hepatitis B

HIV: Human immunodeficiency virus

PMSF: Phenylmethylsulfonyl fluoride

TFA: Trifluoroacetic acid.

\section{Conflict of Interests}

The authors declare that there is no conflict of interests regarding the publication of this paper.

\section{Acknowledgments}

The authors are grateful to Alain Filiatreault and Erica Blais for assistance with analyses and Josée Guénette for technical assistance. This work was supported by the Clean Air Regulatory Agenda, Health Canada.

\section{References}

[1] E. Kaufman and I. B. Lamster, "The diagnostic applications of saliva-a review," Critical Reviews in Oral Biology and Medicine, vol. 13, no. 2, pp. 197-212, 2002.

[2] C. F. Streckfus and L. R. Bigler, "Saliva as a diagnostic fluid," Oral Diseases, vol. 8, no. 2, pp. 69-76, 2002.

[3] A. Segal and D. T. Wong, "Salivary diagnostics: enhancing disease detection and making medicine better," European Journal of Dental Education, vol. 12, no. 1, pp. 22-29, 2008.

[4] C. Streckfus, L. Bigler, T. Dellinger, X. Dai, A. Kingman, and J. T. Thigpen, "The presence of soluble c-erbB-2 in saliva and serum among women with breast carcinoma: a preliminary study," Clinical Cancer Research, vol. 6, no. 6, pp. 2363-2370, 2000.

[5] D. O. Quissell, "Steroid hormone analysis in human saliva," Annals of the New York Academy of Sciences, vol. 694, pp. 143$145,1993$.

[6] R. L. Hodinka, T. Nagashunmugam, and D. Malamud, "Detection of human immunodeficiency virus antibodies in oral fluids," Clinical and Diagnostic Laboratory Immunology, vol. 5, no. 4, pp. 419-426, 1998.

[7] D. Giannessi, M. Maltinti, and S. del Ry, "Adiponectin circulating levels: a new emerging biomarker of cardiovascular risk," Pharmacological Research, vol. 56, no. 6, pp. 459-467, 2007.

[8] M. Toda, R. Tsukinoki, and K. Morimoto, "Measurement of salivary adiponectin levels," Acta Diabetologica, vol. 44, no. 1, pp. 20-22, 2007.
[9] T. F. Luscher and M. Barton, "Endothelins and endothelin receptor antagonists: therapeutic considerations for a novel class of cardiovascular drugs," Circulation, vol. 102, no. 19, pp. 2434-2440, 2000.

[10] A. Inoue, M. Yanagisawa, S. Kimura et al., "The human endothelin family: three structurally and pharmacologically distinct isopeptides predicted by three separate genes," Proceedings of the National Academy of Sciences of the United States of America, vol. 86, no. 8, pp. 2863-2867, 1989.

[11] S. Kaw, M. Hecker, and J. R. Vane, "The two-step conversion of big endothelin 1 to endothelin 1 and degradation of endothelin 1 by subcellular fractions from human polymorphonuclear leukocytes," Proceedings of the National Academy of Sciences of the United States of America, vol. 89, no. 15, pp. 6886-6890, 1992.

[12] M. Yanagisawa, "The endothelin system: a new target for therapeutic intervention," Circulation, vol. 89, no. 3, pp. 1320-1322, 1994.

[13] S. Galatius-Jensen, H. Wroblewski, C. Emmeluth, P. Bie, S. Haunsø, and J. Kastrup, "Plasma endothelin in congestive heart failure: a predictor of cardiac death?" Journal of Cardiac Failure, vol. 2, no. 2, pp. 71-76, 1996.

[14] C.-M. Wei, A. Lerman, R. J. Rodeheffer et al., "Endothelin in human congestive heart failure," Circulation, vol. 89, no. 4, pp. 1580-1586, 1994.

[15] H.-C. Lam, K. Takahashi, M. A. Ghatei, A. N. Warrens, A. J. Rees, and S. R. Bloom, "Immunoreactive endothelin in human plasma, urine, milk, and saliva," Journal of Cardiovascular Pharmacology, vol. 17, no. 7, pp. S390-S393, 1991.

[16] H.-C. Lam, K. Takahashi, M. A. Ghatei, K. Suda, S. M. Kanse, and S. R. Bloom, "Presence of immunoreactive endothelin in human saliva and rat parotid gland," Peptides, vol. 12, no. 4, pp. 883-885, 1991.

[17] R. Denver, A. Tzanidis, P. Martin, and H. Krum, "Salivary endothelin concentrations in the assessment of chronic heart failure," The Lancet, vol. 355, no. 9202, pp. 468-469, 2000.

[18] H.-C. Lam, G.-H. Lo, J.-K. Lee et al., "Salivary immunoreactive endothelin in patients with upper gastrointestinal diseases," Journal of Cardiovascular Pharmacology, vol. 44, no. 1, pp. S413S417, 2004.

[19] M. Bovenzi, F. D’Agostin, F. Rui, L. Ambrosi, and R. Zefferino, "Salivary endothelin and vascular disorders in vibrationexposed workers," Scandinavian Journal of Work, Environment and Health, vol. 34, no. 2, pp. 133-141, 2008.

[20] V. Pickering, R. C. K. Jordan, and B. L. Schmidt, "Elevated salivary endothelin levels in oral cancer patients-a pilot study," Oral Oncology, vol. 43, no. 1, pp. 37-41, 2007.

[21] Y.-S. L. Cheng, T. Rees, L. Jordan et al., "Salivary endothelin-1 potential for detecting oral cancer in patients with oral lichen planus or oral cancer in remission," Oral Oncology, vol. 47, no. 12, pp. 1122-1126, 2011.

[22] L. Ling, J. J. Maguire, and A. P. Davenport, "Endothelin-2, the forgotten isoform: emerging role in the cardiovascular system, ovarian development, immunology and cancer," British Journal of Pharmacology, vol. 168, no. 2, pp. 283-295, 2013.

[23] P. Kumarathasan, P. Goegan, and R. Vincent, "An automated high-performance liquid chromatography fluorescence method for the analyses of endothelins in plasma samples," Analytical Biochemistry, vol. 299, no. 1, pp. 37-44, 2001.

[24] M. Walczak, A. Fedorowicz, S. Chłopicki, and J. SzymuraOleksiak, "Determination of endothelin-1 in rats using a highperformance liquid chromatography coupled to electrospray 
tandem mass spectrometry," Talanta, vol. 82, no. 2, pp. 710-718, 2010.

[25] R. Vincent, P. Kumarathasan, P. Goegan et al., "Inhalation toxicology of urban ambient particulate matter: acute cardiovascular effects in rats," Research Report (Health Effects Institute), vol. 104, pp. 5-54, 2001.

[26] L. Bouthillier, R. Vincent, P. Goegan et al., "Acute effects of inhaled urban particles and ozone: lung morphology, macrophage activity, and plasma endothelin-1," The American Journal of Pathology, vol. 153, no. 6, pp. 1873-1884, 1998.

[27] L. Calderón-Garcidueñas, R. Vincent, A. Mora-Tiscareño et al., "Elevated plasma endothelin-1 and pulmonary arterial pressure in children exposed to air pollution," Environmental Health Perspectives, vol. 115, no. 8, pp. 1248-1253, 2007.

[28] H. H. Chauncey, R. P. Feller, and K. K. Kapur, "Longitudinal agerelated changes in human parotid saliva composition.," Journal of Dental Research, vol. 66, no. 2, pp. 599-602, 1987.

[29] K. M. Höld, D. de Boer, J. Zuidema, and R. A. A. Maes, "Saliva as an analytical tool in toxicology," International Journal of Drug Testing, vol. 1, no. 1, pp. 1-36, 1995.

[30] M. A. Vernace, P. F. Mento, M. E. Maita et al., "Osmolar regulation of endothelin signaling in rat renal medullary interstitial cells," Journal of Clinical Investigation, vol. 96, no. 1, pp. 183-191, 1995.

[31] T. Pfaffe, J. Cooper-White, P. Beyerlein, K. Kostner, and C. Punyadeera, "Diagnostic potential of saliva: current state and future applications," Clinical Chemistry, vol. 57, no. 5, pp. 675687, 2011.

[32] M. S. Ventimiglia, M. R. Rodriguez, V. P. Morales et al., "Endothelins participate in the central and peripheral regulation of submandibular gland secretion in the rat," American Journal of Physiology-Regulatory Integrative and Comparative Physiology, vol. 300, no. 1, pp. R109-R120, 2011.

[33] M. Nakamizo, R. Pawankar, and K. Ohkubo, "Presence of endothelin-1 in human salivary glands and tumors," Nippon Ika Daigaku Zasshi, vol. 65, no. 6, pp. 471-477, 1998.

[34] J. K. M. Aps and L. C. Martens, "Review: the physiology of saliva and transfer of drugs into saliva," Forensic Science International, vol. 150, no. 2-3, pp. 119-131, 2005.

[35] A. Toker, A. Aribas, F. H. Yerlikaya, E. Tasyurek, and K. Akbuğa, "Serum and saliva levels of ischemia-modified albumin in patients with acute myocardial infarction," Journal of Clinical Laboratory Analysis, vol. 27, no. 2, pp. 99-104, 2013.

[36] S. Chiappin, G. Antonelli, R. Gatti, and E. F. De Palo, "Saliva specimen: a new laboratory tool for diagnostic and basic investigation," Clinica Chimica Acta, vol. 383, no. 1-2, pp. 30-40, 2007.

[37] L. R. Stow, M. E. Jacobs, C. S. Wingo, and B. D. Cain, "Endothelin-1 gene regulation," The FASEB Journal, vol. 25, no. 1, pp. 16-28, 2011.

[38] E. Thomson, P. Kumarathasan, and R. Vincent, "Pulmonary expression of preproET-1 and preproET-3 mRNAs is altered reciprocally in rats after inhalation of air pollutants," Experimental Biology and Medicine, vol. 231, no. 6, pp. 979-984, 2006.

[39] R. Shah, "Endothelins in health and disease," European Journal of Internal Medicine, vol. 18, no. 4, pp. 272-282, 2007.

[40] M. K. Glassberg, A. Ergul, A. Wanner, and D. Puett, "Endothelin-1 promotes mitogenesis in airway smooth muscle cells," The American Journal of Respiratory Cell and Molecular Biology, vol. 10, no. 3, pp. 316-321, 1994.

[41] Y. Hirata, T. Emori, S. Eguchi et al., "Endothelin receptor subtype B mediates synthesis of nitric oxide by cultured bovine endothelial cells," Journal of Clinical Investigation, vol. 91, no. 4, pp. 1367-1373, 1993.

[42] D. Montani, R. Souza, C. Binkert et al., "Endothelin-1/endothelin-3 ratio: a potential prognostic factor of pulmonary arterial hypertension," Chest, vol. 131, no. 1, pp. 101-108, 2007.

[43] A. Tsiakalos, G. Hatzis, I. Moyssakis, A. Karatzaferis, P. D. Ziakas, and G. E. Tzelepis, "Portopulmonary hypertension and serum endothelin levels in hospitalized patients with cirrhosis," Hepatobiliary \& Pancreatic Diseases International, vol. 10, no. 4, pp. 393-398, 2011. 

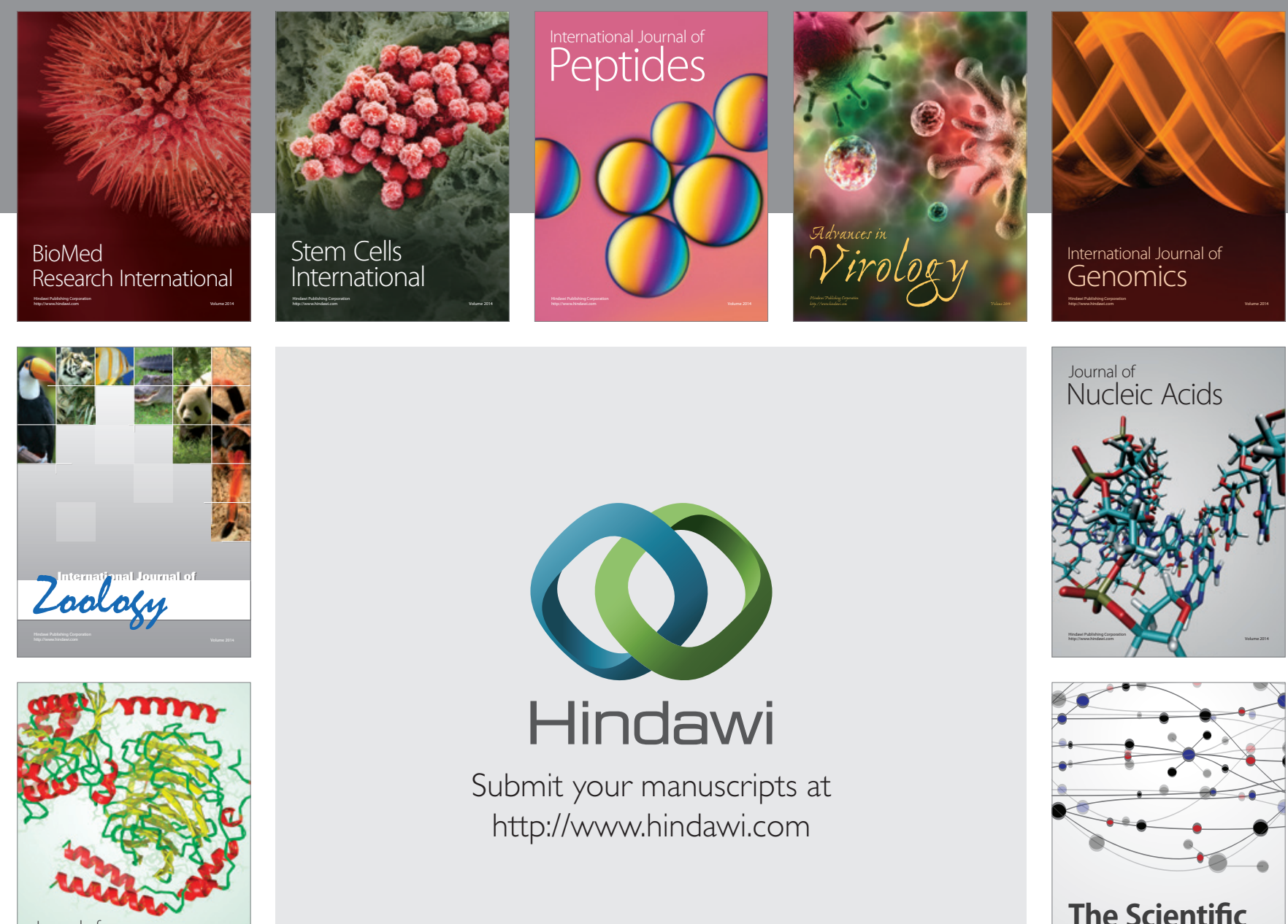

Submit your manuscripts at

http://www.hindawi.com

Journal of
Signal Transduction
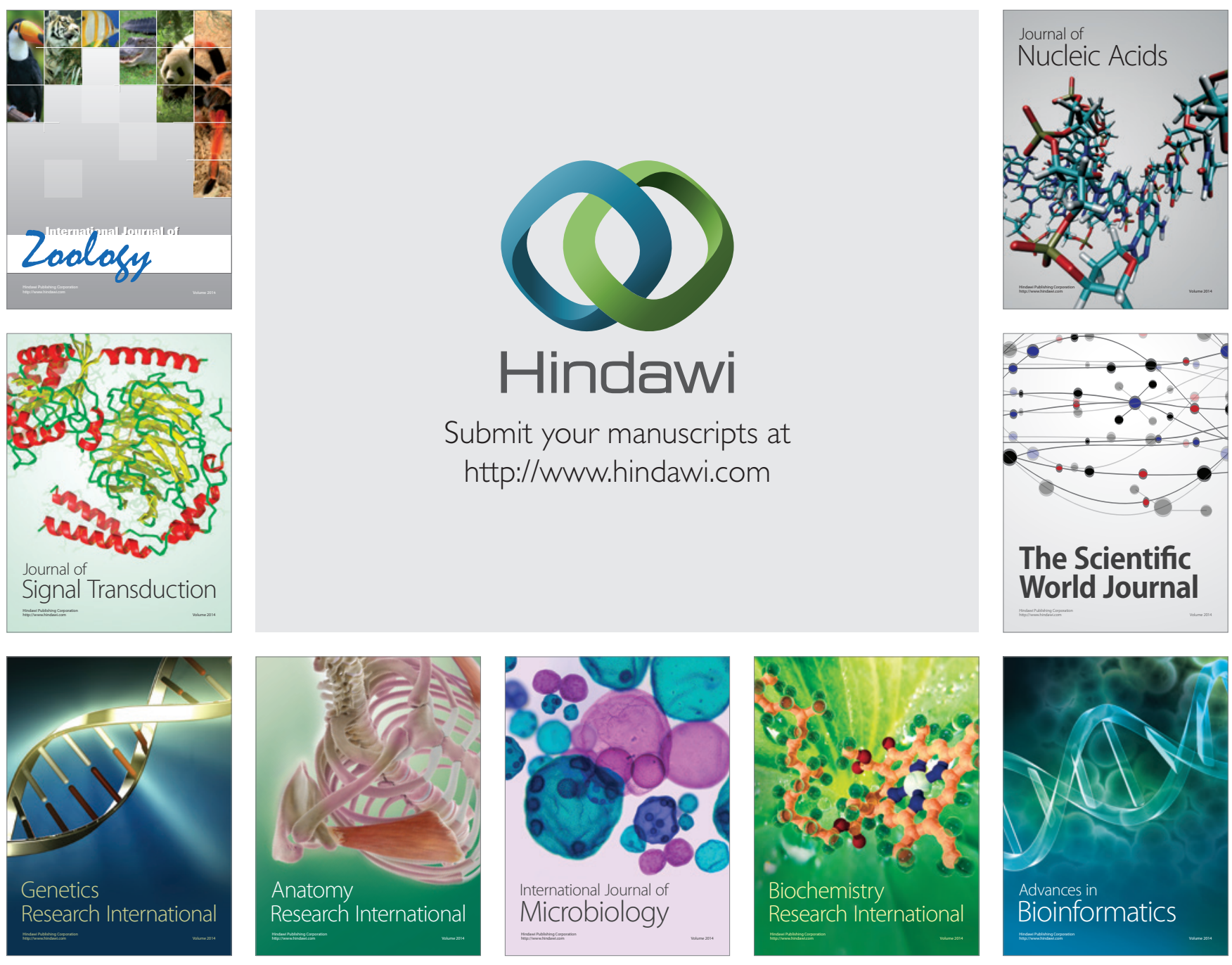

The Scientific World Journal
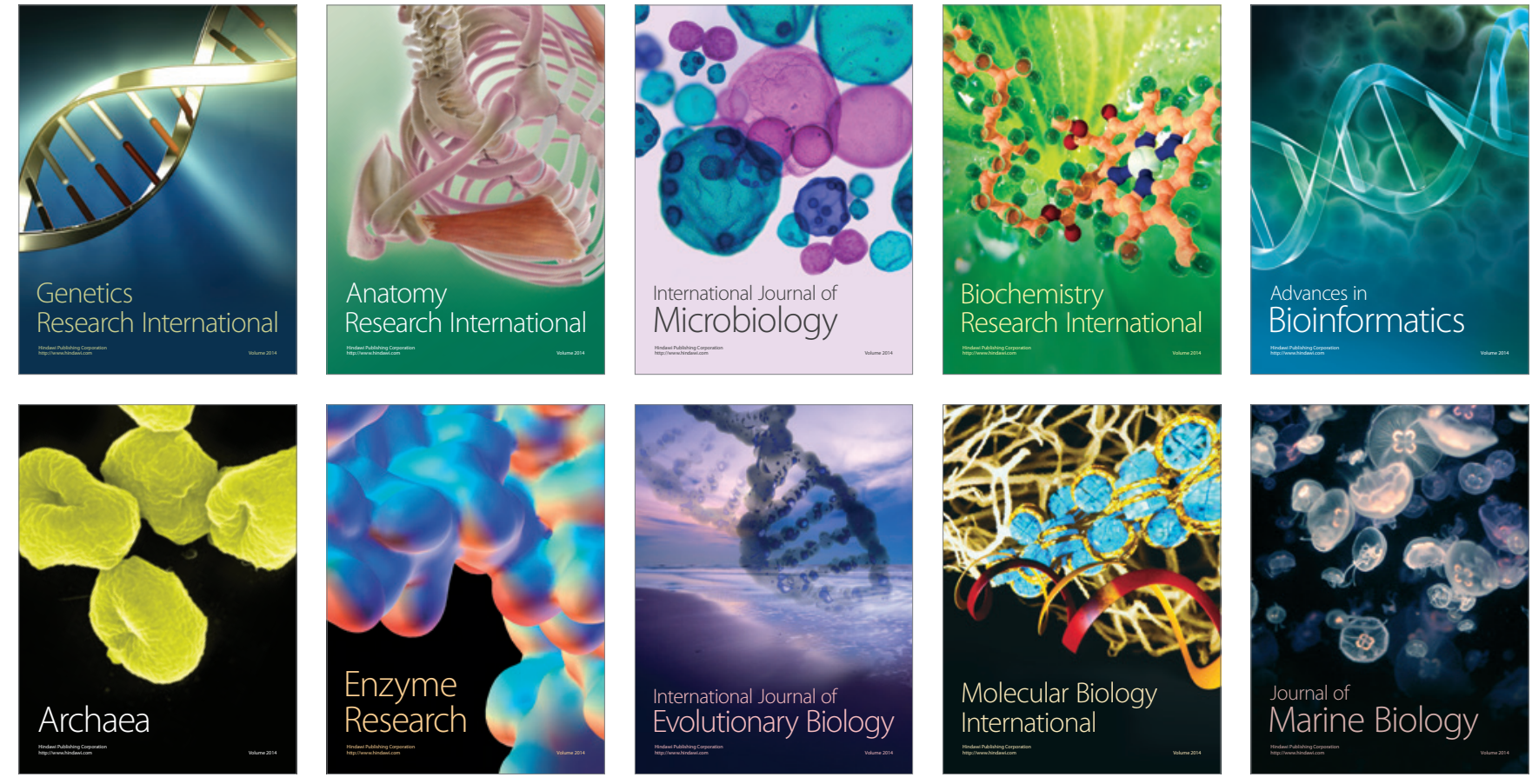